\title{
Efficacy, Safety and Mucosal Healing of Methotrexate in a Large Longitudinal Cohort of Inflammatory Bowel Disease Patients
}

\author{
Carole Rouiller-Braunschweig ${ }^{\mathrm{a}} \quad$ Nicolas Fournier $^{\mathrm{b}} \quad$ Valérie Pittet $^{\mathrm{b}} \quad$ Jean Dudler $^{\mathrm{c}}$ \\ Pierre Michetti ${ }^{d}$ \\ ${ }^{a}$ Faculty of Biology and Medicine, University of Lausanne, Lausanne, Switzerland; ${ }^{b}$ Institute of Social and Preventive \\ Medicine (IUMSP), Lausanne University Hospital, Lausanne, Switzerland; 'Service de Rhumatologie, Médecine \\ Physique et Rééducation, Fribourg, Switzerland; ${ }^{\mathrm{d}}$ Crohn's and Colitis Center, Gastro-entérologie La Source-Beaulieu \\ and Division of Gastroenterology, Centre Hospitalier Universitaire Vaudois, Lausanne, Switzerland
}

\section{Keywords}

Crohn's disease $\cdot$ Ulcerative colitis · Methotrexate

\begin{abstract}
Background/Aims: Evidence for the effectiveness of methotrexate (MTX) in treating inflammatory bowel disease (IBD) is still incomplete. This study assessed the effectiveness, safety and mucosal healing in IBD patients treated with MTX in the Swiss IBD Cohort. Methods: Efficacy was defined by physician assessment or by CD activity index $<150$ points for Crohn's disease (CD) or Modified Truelove and Witts activity index $<4$ points for ulcerative colitis (UC), measured at least after 3 months of MTX therapy. Mucosal healing was evaluated after 3 months or more of therapy. Results: MTX was administered to 341 patients ( 262 CD; $79 \mathrm{UC}$ ) out of 2,660 patients. MTX effectiveness was 59.5\% (128/215) in CD and $40.0 \%$ (24/60) in UC (chi $\left.{ }^{2}=7.2409, p=0.007\right)$. Among patients on MTX therapy at the time of analysis, remission was obtained in $87.4 \%$ (76/87) and 69.2\% (9/13) for CD and UC patients respectively. The median duration of MTX therapy was 40 months for CD and 15 months for UC. Occurrence of adverse events was the first reason for treatment discontinuation (39.4\% of all cases). The rate of mucosal healing with
\end{abstract}

๑ 2017 S. Karger AG, Basel
MTX was $9.5 \%$ for CD and 25\% for UC patients respectively. Conclusion: MTX therapy was effective for the induction and maintenance therapy in IBD patients, with only a modest mucosal healing ability.

(c) 2017 S. Karger AG, Base

\section{Introduction}

Immunosuppressive agents such as azathioprine (AZA), 6-mercaptopurine and methotrexate (MTX) are used to achieve steroid-free remission and as maintenance therapies in inflammatory bowel disease (IBD) patients [1-3]. MTX use in IBD remains limited, in contrast to its wide use in rheumatic inflammatory disorders [4, 5]. These indications for MTX are based on the results of 2 placebo-controlled trials in Crohn's disease (CD), in which MTX was shown to be effective for the induction and maintenance of clinical remission and to decrease the use of corticosteroid [6, 7]. MTX was mostly prescribed as a second-line immunosuppressive therapy after thiopurines (AZA, 6-mercaptopurine). Limited data on the effectiveness of MTX in clinical practice is available, as the use of the drug is limited. In a recent retro-

\section{KARGER}

E-Mail karger@karger.com

www.karger.com/dig
Pierre Michetti, MD

Crohn's and Colitis Cente

Gastro-entérologie La Source-Beaulieu

Avenue Jomini 8, CH-1004 Lausanne (Switzerland)

E-Mail pmichetti@gesb.ch 
spective analysis, MTX had been administered only to $2.1 \%$ of patients, despite effectiveness rates, $64.1 \%$ in CD patients and $47.8 \%$ in ulcerative colitis (UC) patients [8, 9].

MTX is a folate analogue, which binds dihydrofolate reductase and inhibits DNA synthesis resulting in an anti-mitotic action. It also produces an anti-inflammatory action by an increase of adenosine, which decreases proinflammatory cytokines production [5]. Its therapeutic effect takes 8-12 weeks to develop [6]. The induction dose in $\mathrm{CD}$ is $25 \mathrm{mg} /$ week using a parenteral administration (i.m. or s.c.). A dose of $15 \mathrm{mg} /$ week is used by oral administration (p.o.) for maintenance $[1,3]$. MTX side effects are related to the induction of folic acid deficiency $[1,10$, 11]. More than $40 \%$ of IBD patients experienced side effects, mostly liver and gastro-intestinal toxicity, infections and myelotoxicity [8]. Folate supplementation decreases the rate of these side effects [8].

Mucosal healing is nowadays recognized as an important therapeutic endpoint in CD and in UC, associated with a decreased frequency of disease-associated complications, surgeries and hospitalisations [12-14]. The ability of MTX to induce mucosal healing has not been documented in trials and limited evidence is available from case series, especially in UC. In one recent prospective series, Laharie et al. [15] found that mucosal healing was achieved only in $11 \%$ of CD patients treated with MTX, as compared to $50 \%$ with AZA and $60 \%$ with infliximab (IFX). However, the size of this study, $18 \mathrm{CD}$ patients treated with MTX, limits the value of the observation and no data was obtained in UC.

The aim of the current study is to assess the clinical effectiveness, safety and mucosal healing induced by MTX in a large cohort of CD and UC patients.

\section{Methods}

This is a retrospective and longitudinal cohort study conducted in the Swiss IBD Cohort (SIBDC), in which patients diagnosed with CD or UC from all regions of Switzerland have been enrolled since 2005 and are still followed prospectively. For this study, patients with past therapy (before enrolment) or current therapy (at enrolment or during follow-up) with MTX were included. Some patients had therefore 2 courses of MTX. The dose, route of administration and concomitant therapies were recorded. Patients with indeterminate colitis were excluded of this analysis. This study is supported by the Swiss National Science Foundation and was approved by the SIBDC scientific committee as well as by the local ethics committees throughout Switzerland.

Effectiveness was evaluated in 2 different ways for past or current MTX treatment courses. Past treatment efficacy was based on the physician's assessment, as reported in the SIBDC patient enrol- ment questionnaire after MTX discontinuation. For current therapies, treatment response was defined according to the CD activity index and the UC activity index (Lichtiger score or Modified Truelove \& Witts activity index) at least after 3 months of MTX therapy $[16,17]$. Response was defined with a score under 150 points for CD activity index and 4 points for Modified Truelove and Witts activity index. The whole population treated with MTX represents the sum of patients with current and past MTX therapies. Patients with more than one course of therapy were counted only once, as the rate of response did not differ by treatment course in this subpopulation.

Safety information about MTX therapy was collected from the enrolment and yearly follow-up SIBDC cohort questionnaires. The type of adverse reactions and their relation to treatment discontinuation were obtained in the enrolment or follow-up cohort questionnaires at the time of MTX discontinuation, as well as by analysis of abnormalities in the laboratory values (haemoglobin, leukocytes, phosphatase alkaline and folate) of patients with a current MTX therapy.

Mucosal healing was defined as an absence of macroscopic lesions observed during colonoscopic evaluation performed at least 3 months after introduction of MTX. A comparison of the rate of mucosal healing between patients with less or more than 3 months of therapy was conducted.

\section{Statistical Analysis}

All the data was extracted from the SIBDC database and stored at the SIBDC Datacentre in Lausanne, Switzerland. Statistical analyses were performed using STATA version 12.1 (StataCorp, College Station, TX, USA).

Continuous variables are presented as median, interquartile range and range. Categorical variables are presented as absolute numbers and relative frequencies. Categorical data distribution between 2 or more groups were analysed using the chi-square test or the Fisher's exact test, depending on the sample size. MTX treatment duration was analysed as time-to-event data, and the KaplanMeier estimator was used to assess the probability of still being under treatment according to time.

\section{Results}

\section{Demographic and Clinical Features of Patients Included}

From November 2005 until August 2012, 2,660 patients were enrolled in the SIBDC including 1,508 CD, 1,093 UC and 59 IC, which were excluded. In a total of 2,601 patients, 341 (13.1\%) patients were exposed to MTX including $262(17.4 \%)$ with CD and $79(7.2 \%)$ with UC. Among these patients, 231 patients (175 CD, $56 \mathrm{UC})$ had a past MTX therapy and 153 patients (129 CD, 24 UC) had a current MTX therapy. Thirty-four centres provided cases out of 64 centres participating to the SIBDC (53\%). Demographic features of patients at inclusion are listed in Table 1. Montreal classification was used to define the behaviour and location of CD [18]. 
Table 1. Demographic characteristics of patients at enrolment

\begin{tabular}{|c|c|c|c|}
\hline Features & $\mathrm{CD}$ & $\mathrm{UC}$ & Total \\
\hline \multicolumn{4}{|l|}{ Number of patients, $\%$} \\
\hline Total & $262(76.8)$ & $79(23.2)$ & 341 \\
\hline Past MTX therapy & 175 & 56 & 231 \\
\hline Current MTX therapy at inclusion or follow-up & 129 & 24 & 153 \\
\hline \multicolumn{4}{|l|}{ Gender, $n(\%)$} \\
\hline Male & $111(42.4)$ & $46(58.2)$ & $157(46)$ \\
\hline Female & $151(57.6)$ & $33(41.8)$ & $184(54)$ \\
\hline Age at diagnosis, years, median (range) & $26(6-81)$ & $31(13-67)$ & $27(6-81)$ \\
\hline Smokers $(n=333 ; \mathrm{CD}=257 / \mathrm{UC}=76)$ & $117(45.5)$ & $9(11.8)$ & $126(37.8)$ \\
\hline \multicolumn{4}{|l|}{ Behaviour of $\mathrm{CD}, n(\%)$} \\
\hline Inflammatory (B1) & $111(42.4)$ & - & - \\
\hline Stricturing (B2) & $54(20.6)$ & - & - \\
\hline Penetrating (B3) & $97(37.0)$ & - & - \\
\hline Perianal & $69(26.3)$ & - & - \\
\hline \multicolumn{4}{|l|}{ Location, $n(\%)$} \\
\hline Ileal (L1) & $88(33.6)$ & - & - \\
\hline Colonic (L2) & $75(28.6)$ & - & - \\
\hline Ileocolonic (L3) & $89(34.0)$ & - & - \\
\hline Upper digestive tract (only) (L4) & $3(1.1)$ & - & - \\
\hline Other/unknown & $7(2.7)$ & - & - \\
\hline Pancolitis & - & $39(49.4)$ & - \\
\hline Left colitis & - & $33(41.8)$ & - \\
\hline Proctitis & - & $6(7.6)$ & - \\
\hline Other & - & $1(1.3)$ & - \\
\hline
\end{tabular}

Baselines features of all 153 patients (129 CD, 24 UC) with a current MTX therapy at inclusion or during follow-up in the SIBDC are shown in Table 2. Patients with only a past therapy at enrolment are not included in this table, as precise disease phenotype at the time of MTX therapy could not be determined retrospectively in the database. MTX was prescribed as a monotherapy in $27.1 \%$ CD patients and in only one UC patient. Concomitant steroid therapy was observed in $27.9 \%$ of CD patients and in $50.0 \%$ of UC patients. MTX was used as a first-line therapy before thiopurines in $28.1 \%$ of IBD patients.

\section{Clinical Effectiveness of MTX}

In the whole exposed population, effectiveness of MTX was significantly higher in CD than in UC, with a rate of response of $59.5 \%(128 / 215)$ for $\mathrm{CD}$, as compared to $40.0 \%(24 / 60)$ in UC $\left(\mathrm{chi}^{2}=7.2409, p=0.007\right.$; Table 3$)$. Smoking status was not found to affect the response rate in CD.

For patients with current MTX therapies, the effectiveness of MTX in CD was not significantly lower as compared in UC, with a rate of response of $87.4 \%(76 / 87)$ for $\mathrm{CD}$, as compared to $69.2 \%(9 / 13)$ in $\mathrm{UC}\left(\mathrm{chi}^{2}=2.9143\right.$, $p=0.088$, Fischer's exact test 0.103 ; Table 3 ). Patients with an MTX therapy of less than 3 months or without a complete activity index assessment could not be evaluated (42 $\mathrm{CD}$ and $11 \mathrm{UC}$ ).

MTX past therapies could be evaluated only in $206 \mathrm{pa}-$ tients (156 CD, $50 \mathrm{UC}$ ) out of 231 patients (175 CD, 56 UC). Out of $156 \mathrm{CD}$ patients, 77 (49.4\%) has a past therapy evaluated as a response. The rate of response was not significantly lower in UC with a rate of $34.0 \%(17 / 50)$ $\left(\mathrm{chi}^{2}=3.6003, p=0.058\right)$.

\section{Time on Therapy with MTX}

The probabilities for patients with CD or UC to remain on MTX therapy, regardless of the reasons of discontinuation, are shown in a Kaplan-Meier estimator for 111 IBD patients (94 CD, $17 \mathrm{UC}$ ) with a current therapy (Fig. 1). After 15 months, 75\% of CD patients remained on MTX therapy, a value which is $50 \%$ for UC patients, and after 40 months, only $50 \%$ of CD and $25 \%$ of UC are still on MTX therapy. The median treatment duration was 12 months (Table 2), which is a duration long enough to assess response, as MTX typically takes 8-12 weeks to develop effect. However, as the SIBDC only performs a yearly follow-up, our data is not suitable to precisely define time-to-response. 
Table 2. Characteristics of patients with current MTX treatment

\begin{tabular}{|c|c|c|c|}
\hline Features & $\mathrm{CD}$ & $\mathrm{UC}$ & Total \\
\hline Number of patients & 129 & 24 & 153 \\
\hline \multicolumn{4}{|l|}{$\begin{array}{l}\text { Duration of MTX, months, } \\
\text { median (IQR, range), } n=140\end{array}$} \\
\hline$(\mathrm{CD}=118 / \mathrm{UC}=22)$ & $13(1-36,0-108)$ & $5.5(1-22,0-78)$ & $12(1-36,0-108)$ \\
\hline \multicolumn{4}{|l|}{$\begin{array}{l}\text { Way of MTX's administration, } n(\%) \\
n=150(\mathrm{CD}=126 / \mathrm{UC}=24)\end{array}$} \\
\hline Subcutaneous & $94(74.6)$ & $18(75.0)$ & $112(74.7)$ \\
\hline Per os & $32(25.4)$ & $6(25.0)$ & $38(25.3)$ \\
\hline \multicolumn{4}{|l|}{$\begin{array}{l}\text { MTX dose, } \mathrm{mg} / \text { week, median } \\
\text { (IQR, range), } n=151\end{array}$} \\
\hline$(\mathrm{CD}=128 / \mathrm{UC}=23)$ & $15.0(15-20,3.6-30)$ & $15.0(12.5-25,2.5-25)$ & $15.0(15-20,2.5-30)$ \\
\hline Folic acid supplementation, $n(\%)$ & $83(64.3)$ & $14(58.3)$ & $97(63.4)$ \\
\hline \multicolumn{4}{|c|}{ Treatments associated with MTX, $n(\%)$} \\
\hline Salicylates & $12(9.3)$ & $18(75.0)$ & $30(19.6)$ \\
\hline Antibiotics & $3(2.3)$ & $0(0.0)$ & $3(2.0)$ \\
\hline Calcineurin inhibitors & $0(0.0)$ & $2(8.3)$ & $2(1.3)$ \\
\hline Thiopurines & $3(2.3)$ & $0(0.0)$ & $3(2.0)$ \\
\hline Anti-TNFs & $38(29.5)$ & $6(25.0)$ & $44(28.8)$ \\
\hline Steroids & $36(27.9)$ & $12(50.0)$ & $48(31.4)$ \\
\hline Others & $12(9.3)$ & $1(4.2)$ & $13(8.5)$ \\
\hline None (MTX monotherapy) & $35(27.1)$ & $1(4.2)$ & $36(23.5)$ \\
\hline \multicolumn{4}{|l|}{ Treatments before MTX, $n(\%)$} \\
\hline Salicylates & $57(44.2)$ & $14(58.3)$ & $71(46.4)$ \\
\hline Antibiotics & $66(51.1)$ & $8(33.3)$ & $74(48.4)$ \\
\hline Calcineurin inhibitors & $1(0.8)$ & $2(8.3)$ & $3(2.0)$ \\
\hline Thiopurines & $92(71.3)$ & $18(75.0)$ & $110(71.9)$ \\
\hline Anti-TNFs & $42(32.6)$ & $8(33.3)$ & $50(32.7)$ \\
\hline Steroids & $89(69.0)$ & $13(54.2)$ & $102(66.7)$ \\
\hline Others & $12(9.3)$ & $0(0.0)$ & $12(7.8)$ \\
\hline
\end{tabular}

Table 3. MTX therapy efficacy for CD and UC

\begin{tabular}{|c|c|c|c|c|c|c|c|}
\hline \multirow[t]{2}{*}{ Therapy } & \multirow[t]{2}{*}{ Effect } & \multicolumn{2}{|l|}{$\mathrm{CD}$} & \multicolumn{2}{|c|}{ UC } & \multicolumn{2}{|c|}{ Total } \\
\hline & & $n$ & $\%$ & $n$ & $\%$ & $n$ & $\%$ \\
\hline \multirow[t]{3}{*}{ Total } & Response & 128 & 59.5 & 24 & 40.0 & 152 & 55.3 \\
\hline & Non-response & 87 & 40.5 & 36 & 60.0 & 123 & 44.7 \\
\hline & Total & 215 & 100.0 & 60 & 100.0 & 275 & 100.0 \\
\hline \multirow[t]{3}{*}{ Current } & Response & 76 & 87.4 & 9 & 69.2 & 85 & 85.0 \\
\hline & Non-response & 11 & 12.6 & 4 & 30.8 & 15 & 15.0 \\
\hline & Total & 87 & 100.0 & 13 & 100.0 & 100 & 100.0 \\
\hline
\end{tabular}

\section{Safety of MTX}

As side effects were recorded at the time of MTX discontinuation, no data is available about side effects that did not lead to treatment discontinuation. Therefore, only 91 patients were included in this analysis. The prevalence of side effects was the first reason for MTX discon- tinuation in $39.4 \%(91 / 231)$ of cases, $40.0 \%$ for CD (70/175) and $37.5 \%$ for UC (21/56). Details of side effects were reported only for 52 out of 91 patients with side effects by the physicians (39 CD, 13 UC; Table 4). The most frequent side effect was gastrointestinal intolerance in $38.5 \%$ patients ( $43.6 \%$ of $\mathrm{CD}, 23.1 \%$ of $\mathrm{UC}$ ). 
Table 4. MTX side effects (SE) in the order of frequency

\begin{tabular}{|c|c|c|c|c|c|c|}
\hline \multirow[t]{2}{*}{$\mathrm{SE}$} & \multicolumn{2}{|c|}{$\mathrm{CD}$} & \multicolumn{2}{|c|}{ UC } & \multicolumn{2}{|c|}{ Total } \\
\hline & $n$ & $\%$ & $n$ & $\%$ & $n$ & $\%$ \\
\hline Patients with reported type of SE & 39 & 100 & 13 & 100 & 52 & 100 \\
\hline Gastrointestinal intolerance & 17 & 43.6 & 3 & 23.1 & 20 & 38.5 \\
\hline Liver cirrhosis/fibrosis & 5 & 12.8 & 1 & 7.7 & 6 & 11.5 \\
\hline Hypersensitivity reactions & 3 & 7.7 & 1 & 7.7 & 4 & 7.7 \\
\hline Stomatitis/mucositis & 3 & 7.7 & 0 & 0.0 & 3 & 5.8 \\
\hline Opportunistic infections & 2 & 5.1 & 1 & 7.7 & 3 & 5.8 \\
\hline Abdominal pain/diarrhea & 1 & 2.6 & 2 & 15.4 & 3 & 5.8 \\
\hline Cough/pneumonitis & 1 & 2.6 & 1 & 7.7 & 2 & 3.8 \\
\hline Leucopenia/thrombopenia & 1 & 2.6 & 0 & 0.0 & 1 & 1.9 \\
\hline Others & 8 & 20.5 & 4 & 30.8 & 12 & 23.1 \\
\hline
\end{tabular}

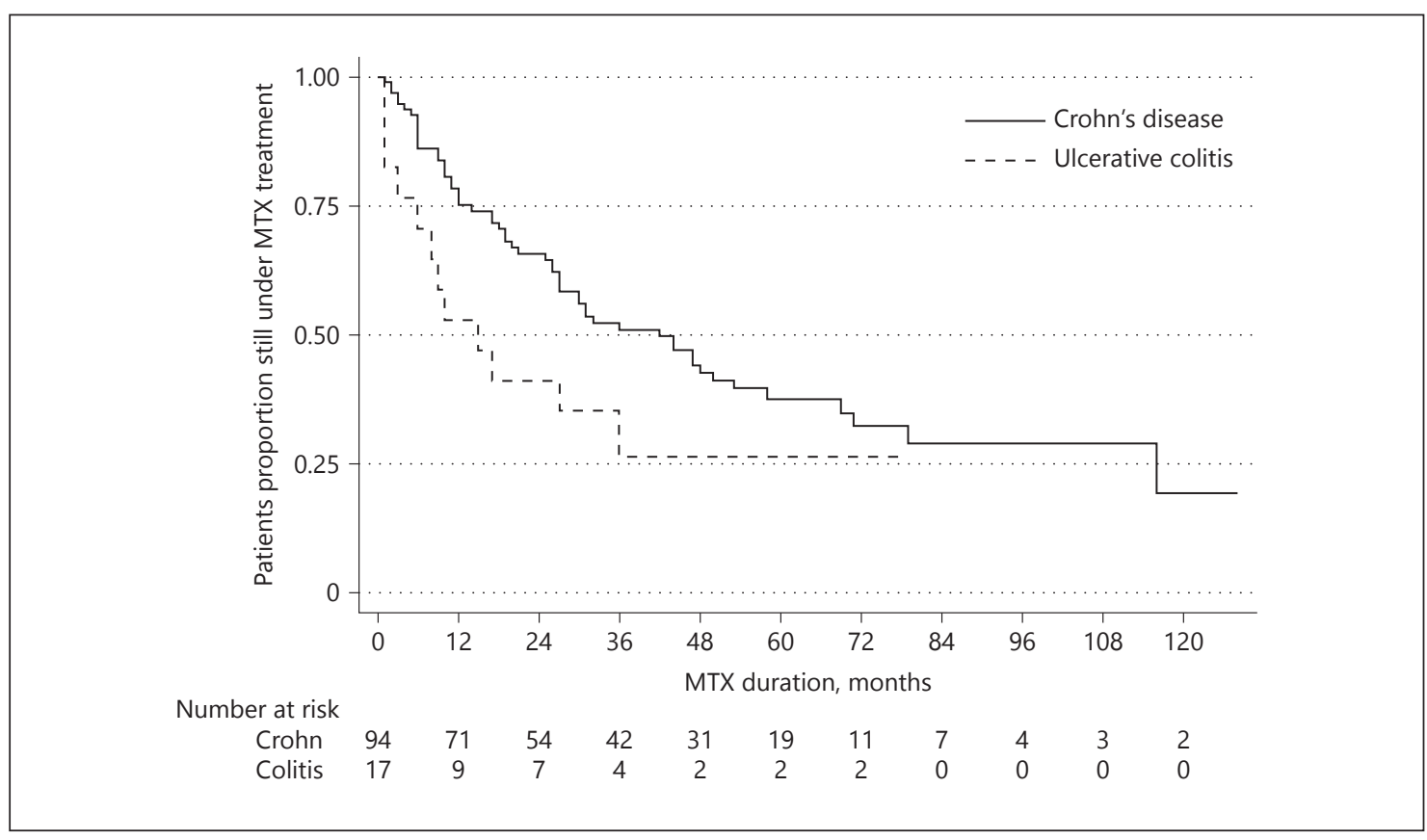

Fig. 1. Kaplan-Meier curves of survival probability to remain on MTX therapy for patients with CD and UC.

The abnormalities in the last laboratory values of patients on current MTX therapy were leucopenia in 4/141 patients (3/119 CD, 1/22 UC), anemia in 16/141 (13/119 CD, 3/22 UC), elevated alkaline phosphatase in $4 / 109$ $(4 / 91 \mathrm{CD}, 0 / 18 \mathrm{UC})$ and low folate values in 10/67 (8/45 $\mathrm{CD}, 2 / 12 \mathrm{UC})$.

\section{Mucosal Healing}

Mucosal healing was observed in 11.8\% (6/51) CD patients with less than 3 months of MTX therapy and in $9.5 \%(4 / 42)$ of patients treated for more than 3 months.
In contrast, in UC patients, mucosal healing was not observed $(0 / 7)$ in patients treated for less than 3 months with MTX, while it was reported in 2 out of 8 patients treated for more than 3 months.

\section{Discussion}

This retrospective and longitudinal study assessed the safety, clinical effectiveness and mucosal healing induced by MTX in a large unselected cohort of CD and UC pa- 
tients. The rate of use of MTX in the SIBDC was 13.1\%, which is higher than previously published [8]. This rate was higher for CD (17.4\%) than for UC (7.2\%). MTX efficacy has been long established in randomised trials for CD, but only recently in UC [19]. It is not surprising, therefore, that in a retrospective and longitudinal study, the rate of use of MTX in both diseases has followed evidence-based medicine, with higher use in CD $[6,7]$. In most cases, MTX was a second-line immunosuppressive therapy after thiopurines, which is in agreement with the prior observations [8]. Furthermore, in our study MTX was rarely used as a monotherapy (Table 2). Interestingly, about one third of patients received MTX after antiTNF failure, which illustrates a potential use of this compound.

\section{Effectiveness}

In the whole population of this study, MTX efficacy was evaluated at $59.5 \%$ for CD and at $40.0 \%$ for UC (Table 3 ), which corresponds to the rate measured in another study that tested a smaller group of patients [8, 20-22]. To our knowledge, the size of the group in the SIBDC represented the larger study ever done which assessed MTX efficacy in IBD patients.

The rate of effectiveness of past MTX therapies was lower than the rate of current therapies (Table 3). This is not surprising in a longitudinal study, as the likelihood of pursuing an effective therapy should obviously be higher than that of pursuing past therapies, which include all the cases with adverse reactions or other causes of treatment discontinuation, especially the wish to conceive a family. Furthermore, effectiveness was assessed in 2 different ways with a past (on the physician's assessment retrospectively) or a current therapy (according to the IBD activity index), which may also affect the results.

The probability for patients with CD or UC to remain on MTX therapy was higher for CD than UC (Fig. 1). The lower effectiveness in UC can partially explain the higher rate of discontinuation of MTX in this condition, as compared to $\mathrm{CD}$. However, the lack of randomized trial to provide a proof of efficacy of MTX in UC probably also influences physicians and patients, leading to the early termination of treatment. This situation may soon change with the full publication of the METEOR study [19]. Another explanation could be that MTX was less effective in $\mathrm{UC}$ than in $\mathrm{CD}$, or that the low mucosal healing rate, which is easier to monitor in UC than in CD, also influenced the decision to maintain the patients under therapy. Furthermore, in this study, MTX was a treatment used in the medium term and not in long term, as shown by the 12-month median duration of current therapies (Table 2). The reason for treatment interruption after established maintenance therapy was a progressive loss of efficacy, observation that confirms the findings of another study [23]. However, a small proportion of patients, in particular with CD, seem to benefit of MTX therapy in the long term.

\section{Safety}

In our study, side effects were the first reason for discontinuation of MTX therapy, at a rate which compares to rates reported previously $[8,21,22]$. Most side effects were benign, like gastrointestinal intolerance (Table 4). Liver cirrhosis/fibrosis was reported by physicians in $11.5 \%$ as the reason for MTX discontinuation. However, only a few patients had abnormalities only in the liver laboratory value collected, which was alkaline phosphatase (in the SIBDC, the original aim was to detect patients with primary sclerosing cholangitis). The use of alkaline phosphatase as a marker of MTX-linked hepatic toxicity is certainly not very sensitive, and could thus have induced an underestimation of the rate of liver intolerance in this patient population. Infections and opportunistic infections (3/52 patients, $5.8 \%$ of side effects) and leucopenia (4/141 patients, $2.8 \%$ ) were uncommon, with lower rates than those reported with other immunosuppressive therapies. Indeed, in some studies, the rate of leucopenia with thiopurines was established between 2.2 and $15 \%[24,25]$. In his retrospective study, Toruner et al. [25] calculated a risk of opportunistic infection significantly increased with the use of corticosteroids (OR 3.3), thiopurines (OR 3.8) or IFX (OR 4.4), but was not significantly increased with a treatment of MTX or mesalamine. Our study confirms that MTX can probably be considered a relatively safe therapy with respect to infectious complications, in comparison to other immunosuppressive therapies for IBD patients. However, because of the high rate of discontinuation due to side effects, patients under MTX should be vaccinated as recommended and carefully monitored for infection [26].

Our study highlighted that folic acid supplements were not prescribed systematically with MTX among SIBDC patients (Table 2), while its systematic use is recommended [1], as folic acid decreases the rate of side effects occurrence [8]. This low rate of use in comparison to other studies could contribute to the high rate of discontinuation due to side effects observed in our study. In the absence of a strict time correlation of the available information regarding prior therapies in the SIBDC da- 
tabase, a statistical analysis of the correlation between the occurrence of side effects and lack of acid folic supplements could however not be conducted.

\section{Mucosal Healing}

In our study, mucosal healing with MTX was considered possibly associated with MTX only when measured of $\mathrm{CD}$ patients achieved a complete mucosal healing, which corresponds to the results of another study [15]. For UC, 2 patients achieved mucosal healing but the population was composed only of 8 patients. The rate of healing was stable for $\mathrm{CD}$ and not for $\mathrm{UC}$ when comparing assessments with treatment duration of less and more than 3 months. With the limitations associated with this very limited dataset, the efficacy of mucosal healing seemed to be earlier for CD than for UC, and lower as compared to the mucosal healing rates achieved with

\section{Limitations}

Some methodological limitations can be identified in the present study. First, the results were assessed with different parameters, depending whether MTX therapy was current or only described in the patient's past medical history, making patients not strictly comparable for some study endpoints. Second, the follow-up of patients was performed only once a year, limiting the collection of intercurrent events in the follow-up, such as short relapses or time limited side effects, which may be prone to recollection bias. Third, the yearly follow-up also implies that some information may be missing to fully understand medical decisions, like the reasons for treatment discontinuation. Finally, the yearly response rate measured with an activity index once a year is far from being precise. However, despite these limitations, the SIBDC provides one of the more precise follow-up of longitudinal cohorts, with the overall physician decisions and current therapies precisely collected, making the actual treatment rates valid.

\section{Conclusion}

This retrospective and longitudinal study suggests that MTX is a useful therapy for IBD, in particular for CD, with a treatment duration that extends beyond one year, which is comparable to other therapies. In UC, MTX showed an effectiveness that compares to CD, but therapy is often of shorter duration. Mucosal healing with MTX for both IBD indications was low. after at least 3 months of therapy. Only a small proportion AZA or IFX [15].

The real potential of MTX in IBD is still poorly evaluated, and the results of the first randomized trial testing MTX against placebo in UC are awaited. Because this treatment is cheap, well tolerated and associated with a low risk of opportunistic infections, further studies evaluating its potential in combination therapy with biological therapies, including anti-TNF and anti-integrin antibodies should be encouraged.

\section{Acknowledgements}

The authors thank all the practicing gastroenterologists in Switzerland who contributed cases to the Swiss IBD Cohort over its 10 years of existence. The work performed by the study nurses in each contributing center as well as the work of the DataCenter team is here acknowledged.

\section{Disclosure Statements}

The manuscript, including related data, figures and tables has not been previously published and the manuscript is not under consideration in another journal or book.

Financial conflict of interest: none of the authors report any conflict of interest in relation to this study.

\section{Funding Sources}

The study is supported by the Swiss National Science Foundation grants No. 33CS30-148422 (SIBDC study), 32473B-138498 (Appropriateness of care in IBD) and by the Foundation for Digestive and Liver Disease, Lausanne, Switzerland.

\section{References}

1 Dignass A, Van Assche G, Lindsay JO, Lémann M, Söderholm J, Colombel JF, et al: The second European evidence-based consensus on the diagnosis and management of Crohn's disease: current management. J Crohns Colitis 2010;4:28-62.

2 Dignass A, Lindsay JO, Sturm A, Windsor A, Colombel JF, Allez M, et al: Second European evidence-based consensus on the diagnosis and management of ulcerative colitis part 2: current management. J Crohns Colitis 2012; 6:991-1030.

3 Felley C, Mottet C, Hess J, Maillard MH, Delarive J, Michetti P: Maladies inflammatoires de l'intestin. Nouveautés en Médecine 2008. 2009;187:185-194.

4 Purcell WT, Ettinger DS: Novel antifolate drugs. Curr Oncol Rep 2003;5:114-125.

5 Cutolo M, Sulli A, Pizzorni C, Seriolo B, Straub RH: Anti-inflammatory mechanisms of methotrexate in rheumatoid arthritis. Ann Rheum Dis 2001;60:729-735.

Rouiller-Braunschweig/Fournier/Pittet/ Dudler/Michetti 
6 Feagan BG, Rochon J, Fedorak RN, Irvine EJ, Wild G, Sutherland L, et al: Methotrexate for the treatment of Crohn's disease. The North American Crohn's Study Group Investigators. N Engl J Med 1995;332:292-297.

7 Feagan BG, Fedorak RN, Irvine EJ, Wild G, Sutherland L, Steinhart AH, et al: A comparison of methotrexate with placebo for the maintenance of remission in Crohn's disease. North American Crohn's Study Group Investigators. N Engl J Med 2000;342:1627-1632.

8 Saibeni S, Bollani S, Losco A, Michielan A, Sostegni R, Devani M, et al: The use of methotrexate for treatment of inflammatory bowel disease in clinical practice. Dig Liver Dis 2012; 44:123-127.

9 Manz M, Vavricka SR, Wanner R, Lakatos PL, Rogler G, Frei P, et al: Therapy of steroid-resistant inflammatory bowel disease. Digestion 2012;86(suppl 1):11-15.

$10 \mathrm{Al} \mathrm{VKB}$ et. Les maladies inflammatoires chroniques de l'intestin?: "survival kit" pour internistes et généralistes. Nouveautés en Gastroentérologie et Hépatologie 2010;233:180185.

11 http://www.compendium.ch/mpro/ $\mathrm{mnr} / 23130 / \mathrm{html} / \mathrm{fr} \# 7100$.

12 Geboes K, Rutgeerts P, Opdenakker G, Olson A, Patel K, Wagner CL, et al: Endoscopic and histologic evidence of persistent mucosal healing and correlation with clinical improvement following sustained infliximab treatment for Crohn's disease. Curr Med Res Opin 2005;21:1741-1754.

13 Colombel JF, Rutgeerts P, Reinisch W, Esser D, Wang Y, Lang Y, et al: Early mucosal heal- ing with infliximab is associated with improved long-term clinical outcomes in ulcerative colitis. Gastroenterology 2011;141: 1194-1201.

14 Frøslie KF, Jahnsen J, Moum BA, Vatn MH: Mucosal healing in inflammatory bowel disease: results from a Norwegian populationbased cohort. Gastroenterology 2007;133: 412-422.

15 Laharie D, Reffet A, Belleannée G, Chabrun E, Subtil C, Razaire S, et al: Mucosal healing with methotrexate in Crohn's disease: a prospective comparative study with azathioprine and infliximab. Aliment Pharmacol Ther 2011;33: 714-721.

16 Lichtiger S, Present DH, Kornbluth A, Gelernt I, Bauer J, Galler G, et al: Cyclosporine in severe ulcerative colitis refractory to steroid therapy. N Engl J Med 1994;330:1841-1845.

17 Best WR, Becktel JM, Singleton JW, Kern F Jr: Development of a Crohn's disease activity index. National Cooperative Crohn's Disease Study. Gastroenterology 1976;70:439-444.

18 Spekhorst LM, Visschedijk MC, Alberts R, Festen EA, van der Wouden EJ, Dijkstra G, et al: Performance of the Montreal classification for inflammatory bowel diseases. World J Gastroenterol 2014;20:15374-15381.

19 Carbonnel F, Colombel JF, Filippi J, Katsanos K, Peyrin-Biroulet L, Allez M, et al: 745 methotrexate for corticosteroid-dependent ulcerative colitis: results of a placebo randomized controlled trial. Gastroenterology 2015;148: S140.

20 Soon SY, Ansari A, Yaneza M, Raoof S, Hirst J, Sanderson JD: Experience with the use of low-dose methotrexate for inflammatory bowel disease. Eur J Gastroenterol Hepatol 2004;16:921-926.

21 Lémann M, Zenjari T, Bouhnik Y, Cosnes J, Mesnard B, Rambaud JC, et al: Methotrexate in Crohn's disease: long-term efficacy and toxicity. Am J Gastroenterol 2000;95:17301734.

22 Hausmann J, Zabel K, Herrmann E, Schröder $\mathrm{O}$ : Methotrexate for maintenance of remission in chronic active Crohn's disease: longterm single-center experience and meta-analysis of observational studies. Inflamm Bowel Dis 2010;16:1195-1202.

23 González-Lama Y, Taxonera C, López-Sanromán A, Pérez-Calle JL, Bermejo F, Pajares $\mathrm{R}$, et al: Methotrexate in inflammatory bowel disease: a multicenter retrospective study focused on long-term efficacy and safety. The Madrid experience. Eur J Gastroenterol Hepatol 2012;24:1086-1091.

24 Bär F, Sina C, Fellermann K: Thiopurines in inflammatory bowel disease revisited. World J Gastroenterol 2013;19:1699-1706.

25 Toruner M, Loftus EV Jr, Harmsen WS, Zinsmeister AR, Orenstein R, Sandborn WJ, et al: Risk factors for opportunistic infections in patients with inflammatory bowel disease. Gastroenterology 2008;134:929-936.

26 Rahier JF, Magro F, Abreu C, Armuzzi A, Ben-Horin S, Chowers Y, et al: Second European evidence-based consensus on the prevention, diagnosis and management of opportunistic infections in inflammatory bowel disease. J Crohns Colitis 2014;8:443468 